\title{
Small-scale temporal and spatial variability in foraging behaviour of the mid-shore gastropod Nerita yoldii on seasonal, tropical, rocky shores
}

\author{
Ariel Chung Yan Yeung, Gray A. Williams* \\ The Swire Institute of Marine Science and Division of Ecology \& Biodiversity, School of Biological Sciences, \\ The University of Hong Kong, Pokfulam Road, Hong Kong SAR
}

\begin{abstract}
Describing temporal variation in the foraging behaviour of intertidal gastropods is important to gain an understanding of the environmental conditions that constrain their activity patterns. Foraging behaviour in the tropical gastropod Nerita yoldi was mainly determined by the tidal cycle: individuals foraged when they were awash, or emersed when the rock was wet, migrating downshore to forage and upshore when they returned to refuges. Apart from tidal influences, foraging in $N$. yoldii also varied with season and tidal state. Individuals were generally more active in summer than in winter and on neap than spring tides; although small-scale daily variation existed. Such temporal variation may be caused by several interacting environmental variables, especially air temperature, pressure and irradiance, which influence physical conditions as well as individuals' metabolism. Individual foraging patterns were also highly labile between seasons: most individuals would stop and remain stationary on the open rock surface in winter, but returned to refuges after foraging in summer, a pattern probably driven by physical stress. The foraging behaviour of N. yoldii, therefore, is predictable on a coarse scale, in terms of when they are active, but highly labile in duration and foraging range, which indicates the importance of local, daily variation in environmental factors controlling foraging on shores that have strong temporal changes in abiotic conditions.
\end{abstract}

KEY WORDS: Nerita $\cdot$ Foraging behaviour $\cdot$ Tropical shore

\section{INTRODUCTION}

Variation in the temporal and spatial distribution of foraging behaviour in intertidal organisms is important in mediating the interactions between different species, which in turn can influence community structure (Hawkins \& Hartnoll 1983, Chapman \& Underwood 1992a, Williams et al. 1999, Williams \& Little 2007). The timing of foraging of nearly all intertidal grazers shows some tidal correlation, presumably driven by physical stress or predation risk (Little 1989, Chapman \& Underwood 1992a). Foraging be- haviour can, however, be labile within the same species, varying temporally, for example, with different seasons ( $\mathrm{Ng} \&$ Williams 2006) and diurnal and tidal cycles (Chelazzi 1982, Santini et al. 2004, 2011). Such behaviour can also vary spatially with different site locations (Hartnoll \& Wright 1977), habitats (Hawkins \& Hartnoll 1982, Williams et al. 1999) and tidal levels (Williams \& Morritt 1991). These differences are probably due to local variation in environmental factors, which can be causal in driving foraging behaviour or inhibiting activity when conditions are unfavourable (Little et al. 1988, Williams \& Little 2007). 
Such lability in foraging behaviour represents important adaptive traits in organisms (Mery \& Burns 2010). Climatic seasonality, for example, is a large time-scale temporal pattern that affects foraging behaviour owing to changes in physical stress, predation pressure and food availability as well as associated changes in tidal and diurnal conditions. As a result, such variation in foraging behaviour can make it difficult to define precise behavioural patterns of a species (Chapman \& Underwood 1992a, Ng \& Williams 2006, Santini et al. 2011).

The gastropod genus Nerita Linnaeus 1758 (Neritacea) has a high abundance and diversity in tropical regions (Vermeij 1973). Most species, such as N. textilis (Chelazzi et al. 1983) and N. polita (Chelazzi 1982) are zonal shuttlers (Chelazzi et al. 1988), which forage from a refuge either up- or downshore during each tidal cycle before returning to their resting level (Chelazzi et al. 1988). Previous observations on the behaviour of Nerita have not, however, investigated longer-term variations in foraging patterns, such as monthly or seasonal variation, although a longerterm study of $N$. plicata, $N$. textilis and $N$. undata in Kenya showed these species to be more active on spring than neap tides (Ruwa \& Jaccarini 1988).

Nerita are important herbivores in the Hong Kong rocky intertidal zone (Hill 1980). In contrast to other tropical localities where the foraging behaviour of Nerita has been studied (e.g. Panama, Levings \& Garrity 1983), Hong Kong has a strongly seasonal climate, with hot, wet summers and cool, dry winters (Kaehler \& Williams 1996). In addition, Hong Kong's tidal cycle also shows temporal variation, from semidiurnal (two unequal tides a day during spring tides, with $\sim 2.5 \mathrm{~m}$ tidal range) to almost diurnal tides (one tide a day, with $\sim 1.0 \mathrm{~m}$ tidal range, during neap tides, Morton et al. 1996). As a result, rocky shores experience great temporal variation in environmental factors, which are likely to influence foraging behaviour patterns of intertidal gastropods (Santini et al. 2011).

The present study investigated large and small scale patterns of temporal variation (with season and monthly cycles) in the foraging behaviour of an abundant nerite, Nerita yoldii. The aim of this study was to identify the general patterns of foraging of $N$. yoldii to determine the overall rhythms that constrain the behavioural repertoire of this species. Observations of smaller-scale (e.g. daily) variation in foraging behaviour, and associated causal factors, were undertaken to examine how labile the behaviour of this species can be, and to describe how N. yoldii may respond to local, environmental changes.

\section{MATERIALS AND METHODS}

\author{
Study sites
}

Two gently sloping sites (Site 1, 9 and Site 2, 5 m wide, $\sim 17^{\circ}$ slope), $\sim 20 \mathrm{~m}$ apart, were selected at Lung Kwu Tan, Hong Kong $\left(22^{\circ} 15^{\prime} \mathrm{N}, 114^{\circ} 10^{\prime} \mathrm{E}\right)$ between 1.25 and $1.75 \mathrm{~m}$ above chart datum (CD; i.e. the height of the lowest astronomical tide), which is the most abundant zone of Nerita yoldii (Yeung 2006). The high shore ( $>1.75 \mathrm{~m}$ above $\mathrm{CD})$ at both sites appeared barren, whilst the mid and low shores were covered by a layer of biofilm from June to December and a low turf of macroalgae (Ulva spp., Enteromorpha spp.) from January to May (Yeung 2006). At both study sites, a $50 \times 50 \mathrm{~cm}$ grid of small holes was drilled in the rock, into which a $50 \times 50 \mathrm{~cm}$ aluminum quadrat (evenly divided using nylon lines to form 100 $5 \times 5 \mathrm{~cm}$ squares) could be fitted via adjustable, $15 \mathrm{~cm}$ long, screw legs at each corner of the quadrat, which held the quadrat over the rock surface.

\section{Observations of foraging behaviour}

To investigate temporal variation in the foraging behaviour of Nerita yoldii, observations were conducted for $24.5 \mathrm{~h}$ on 6 occasions in summer 2003 and winter 2003/2004: 3 times during spring tides (daily tidal range, $>2 \mathrm{~m}$ ) and 3 times during neap tides (daily tidal range, $<1.25 \mathrm{~m}$ ). On each randomly chosen sampling date, 18 different individuals (size, $14.4 \pm 2.1 \mathrm{~mm}$ [mean $\pm \mathrm{SD}])$ were tagged $24 \mathrm{~h}$ before observation $(\Sigma \mathrm{n}=2$ sites $\times 2$ seasons $\times 2$ tidal conditions $\times 3 \mathrm{~d} \times 18$ individuals per observation $=432$ ).

At $30 \mathrm{~min}$ intervals, the location of tagged individuals was determined to the nearest $2.5 \times 2.5 \mathrm{~cm}$ square, by recording the corner of the respective $5 \times$ $5 \mathrm{~cm}$ square of the quadrat that the individual was closest to (e.g. upper left) when viewed in the perpendicular plane. To do this at night, a red filtered light was used, which did not appear to disturb the nerites (see Little et al. 1988). Preliminary observations showed that Nerita yoldii are inactive and do not move when they are submerged during high tide. Observations were, therefore, not made when tagged individuals were immersed by the tide, as they were assumed to be inactive.

The environmental conditions experienced by individuals were defined as:

(1) immersed by the tide (an individual that was completely submerged by the tide); (2) immersed in a pool (an individual that was completely submerged 
in a pool); (3) awash (an individual that was washed by waves on the ebbing or rising tide); (4) wet, emersed (an individual located in any wet microhabitat, but not washed by waves or submerged by the tide or in a pool; an individual partially submerged in a pool was also considered as wet, emersed); and (5) dry, emersed (an individual located in any dry habitat).

To investigate the influence of temperature variables on individuals' foraging behaviour, air $(\sim 5 \mathrm{~cm}$ above the rock surface), seawater, dry and wet rock surfaces and crevice temperatures were measured hourly during each observation period $\left( \pm 0.1^{\circ} \mathrm{C}, \mathrm{n}=5\right)$ at both study sites with an Omega K-type (Teflon insulated) thermocouple (diameter, $0.25 \mathrm{~mm}$ ) connected to a portable thermometer (Omega).

Study sites were revisited at low tide and the position of each individual, measured at each half-hour interval, was relocated on the rock surface. A preliminary study showed that the error of this scoring method was $11.25 \pm 7.3 \mathrm{~mm}$ ( $\mathrm{n}=20$, Yeung 2006). To account for the influence of surface complexity (see Erlandsson et al. 1999), the shortest distance traveled by an individual between 2 successive recorded locations was measured using a chain (link length, $5 \mathrm{~mm}$ ) laid on the rock surface to follow the rock contour.

\section{Data analysis}

A foraging excursion was defined as the duration of movement of an individual from being stationary, usually in a refuge (crevice or pool), onto the open rock surface, and then back to become stationary, again usually in a refuge. To estimate the direction of each foraging excursion, the direction $\left( \pm 1^{\circ}\right.$, measured by protractor, with $0^{\circ}$ indicating upshore and $180^{\circ}$ downshore) and displacement $( \pm 1 \mathrm{~mm})$ that individuals moved from (1) their initial refuge to the furthest traveled point (outward phase = foraging range), and (2) the furthest point to the subsequent final refuge (return phase), were measured (after Chelazzi et al. 1983).

The displacement $(R)$ and direction $(\Phi)$ of resultant vectors of outward and return phases during different seasons and tidal conditions were calculated using circular statistics (Batschelet 1981). To investigate if individuals exhibited non-random movement (i.e. directional movement) when on the outward and return phases to and from the furthest traveled points, Rayleigh's test (see Batschelet 1981, Chapman \& Underwood 1992b) was used to deter- mine if the direction of the resultant vector differed significantly from random during different seasons and tidal conditions.

Percentage activity (\%) was calculated as the percentage of individuals exhibiting movement at a particular time. Other parameters used to investigate the foraging behaviour of the traced individuals were: (1) total distance traveled $(\mathrm{cm}$, the sum of the distance traveled by an individual during a foraging excursion); (2) foraging range (cm, the maximum displacement of an individual from its initial refuge during a foraging excursion); (3) maximum speed $\left(\mathrm{cm} \mathrm{min}^{-1}\right.$, the maximum speed achieved by an individual during a foraging excursion) and (4) activity duration (h, the total duration that an individual was active during a foraging excursion).

To investigate temporal variation in foraging parameters, a 3-way, mixed model ANOVA was conducted with season (2 levels, summer and winter; fixed and orthogonal), tidal condition (2 levels, spring and neap tides; fixed and orthogonal) and sampling date ( $3 \mathrm{~d}_{\text {; }}$ random, nested within season and tidal condition). Within this model, there is no replication of the factor 'season' (as only one winter and summer period were sampled); therefore, a significant seasonal effect has to be interpreted as specific to the year of investigation. Data from the 2 sites were pooled $(\Sigma \mathrm{n}=18 \times 2=36)$ prior to analysis for each day to increase statistical power as there was no significant difference ( $t$-tests: $p>0.05)$ in mean values of the various parameters between the 2 sites. Data were checked for normality and homogeneity of variances, and transformed where necessary. Significant fixed factors were further analyzed using StudentNewman-Keuls (SNK) multiple comparison tests (Zar 1999).

\section{RESULTS}

\section{Environmental variables}

On the 12 observation days, seawater temperature ranged from 27 to $32^{\circ} \mathrm{C}$ in summer and from 15 to $22^{\circ} \mathrm{C}$ in winter, which was similar to the air temperature $\left(27\right.$ to $31^{\circ} \mathrm{C}$ in summer, 15 to $19^{\circ} \mathrm{C}$ in winter; Table 1). The temperature on the dry rock surface was relatively higher $\left(27\right.$ to $34^{\circ} \mathrm{C}$ in summer, 13 to $25^{\circ} \mathrm{C}$ in winter) than in crevices (26 to $33^{\circ} \mathrm{C}$ in summer, 14 to $22^{\circ} \mathrm{C}$ in winter) or on the wet rock surface $\left(26\right.$ to $32^{\circ} \mathrm{C}$ in summer, 13 to $20^{\circ} \mathrm{C}$ in winter; Table 1). 
Table 1. Nerita yoldii. Summary (mean, $\mathrm{n}=96$ ) of seawater, air, crevice, wet rock surface and dry rock surface temperatures on the $12 \mathrm{~d}$ used to observe foraging behaviour

\begin{tabular}{|c|c|c|c|c|c|c|c|}
\hline \multirow[b]{2}{*}{ Season } & \multirow[b]{2}{*}{ Tide } & \multirow[b]{2}{*}{ Day } & \multicolumn{5}{|c|}{$\longrightarrow$ Temperature $\left({ }^{\circ} \mathrm{C}\right)$} \\
\hline & & & Seawater & Air & Crevice & $\begin{array}{c}\text { Dry rock } \\
\text { surface }\end{array}$ & $\begin{array}{c}\text { Wet rock } \\
\text { surface }\end{array}$ \\
\hline \multirow[t]{6}{*}{ Summer } & Spring & 1 & 31.1 & 30.3 & 32.3 & 33.3 & 31.9 \\
\hline & & 2 & 29.6 & 28.9 & 30.8 & 30.9 & 29.9 \\
\hline & & 3 & 29.1 & 29.3 & 31.2 & 31.6 & 30.3 \\
\hline & Neap & 1 & 29.8 & 30.9 & 33.2 & 33.4 & 30.8 \\
\hline & & 2 & 27.8 & 27.4 & 26.7 & 27.7 & 26.2 \\
\hline & & 3 & 29.2 & 29.3 & 32.5 & 33.7 & 29.9 \\
\hline \multirow[t]{6}{*}{ Winter } & Spring & 1 & 21.3 & 16.5 & 20.7 & 22.2 & 19.4 \\
\hline & & 2 & 19.1 & 18.8 & 21.9 & 25.1 & 21.8 \\
\hline & & 3 & 15.8 & 13.0 & 14.3 & 13.6 & 13.9 \\
\hline & Neap & 1 & 18.8 & 15.4 & 17.7 & 16.5 & 15.4 \\
\hline & & 2 & 18.6 & 18.4 & 19.6 & 19.2 & 18.2 \\
\hline & & 3 & 15.5 & 18.0 & 20.6 & 20.5 & 18.9 \\
\hline
\end{tabular}

\section{Foraging behaviour of Nerita yoldii}

The foraging behaviour of Nerita yoldii was closely related with the tidal cycle. When the tidal level was $>1.75 \mathrm{~m}$ above $\mathrm{CD}$ (when nearly all individuals were immersed), activity was very low (Figs. 1-3, for individual days see Fig. S1A-D in the Supplement at www.int-res.com/articles/suppl/ b016p177_supp.pdf). Activity began on the ebbing tide and ended when individuals were wet by the rising tide, and was low when individuals were on dry substratum (Figs. 1-3). Activity peaks in summer were usually $\sim 60 \%$ of the studied populations, with an occasional high of $\sim 90 \%$ on both spring and neap tide days. In winter, the percentage activity varied greatly on different days, between $\sim 5$ and $60 \%$ (Fig. 1).
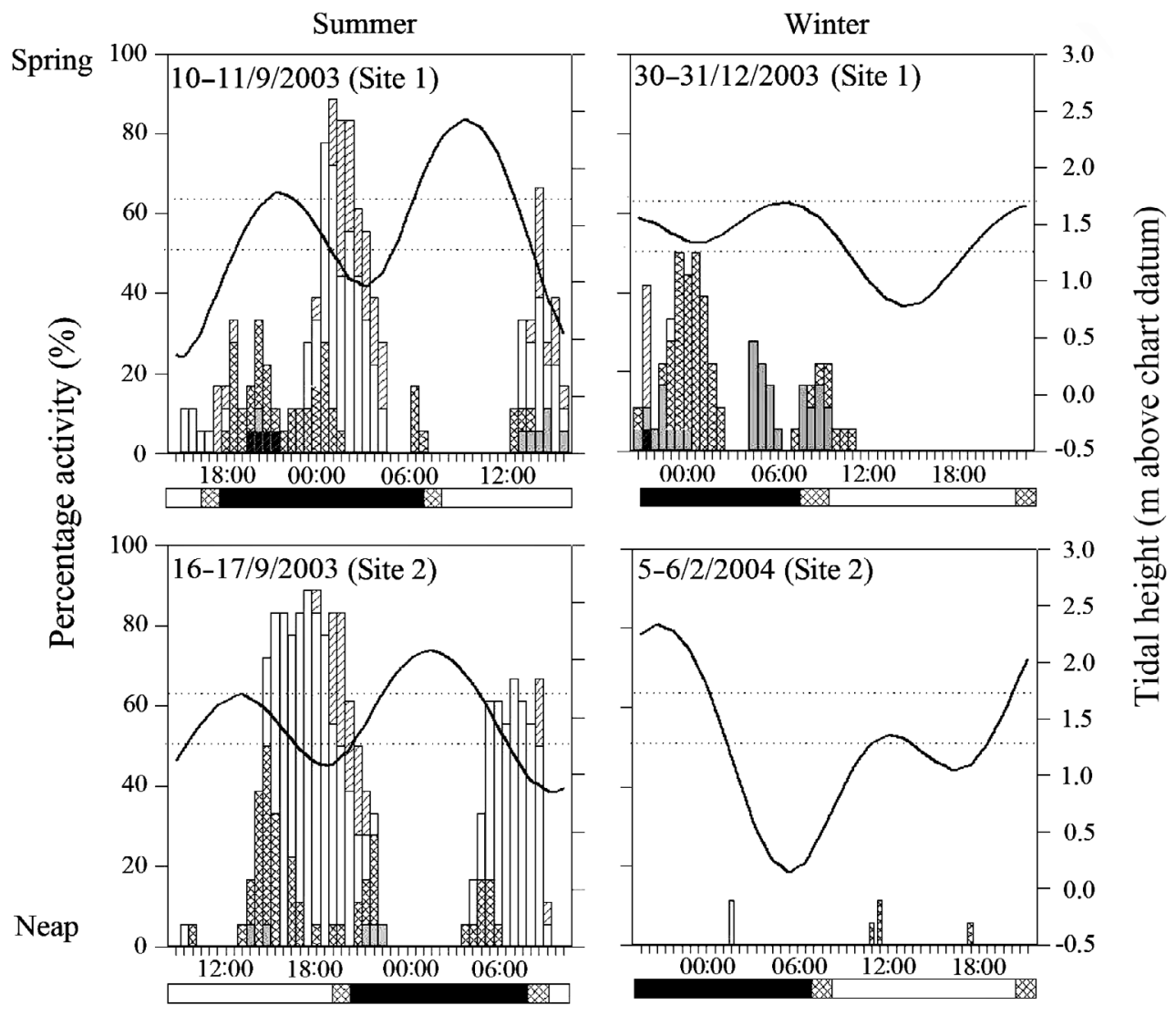

Time (h)

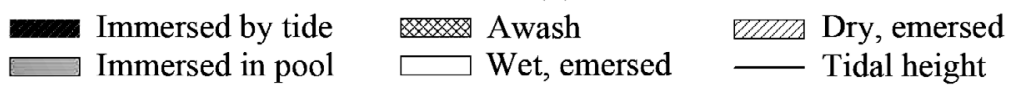

Fig. 1. Nerita yoldii. Representative examples of the tidal cycle and variation in the percentage activity of $N$. yoldii, separated into different conditions at Sites 1 and 2, on $1 \mathrm{~d}$ of each season and tidal condition, $\mathrm{n}=18$. Open horizontal bars indicate daytime, solid bars nighttime and hatched bars dusk or dawn. Dotted horizontal lines delimit the abundant zone of tracked individuals (results for individual days are given in Fig. S1A-D in the Supplement at www.int-res.com/articles/suppl/b016p177_supp.pdf) 


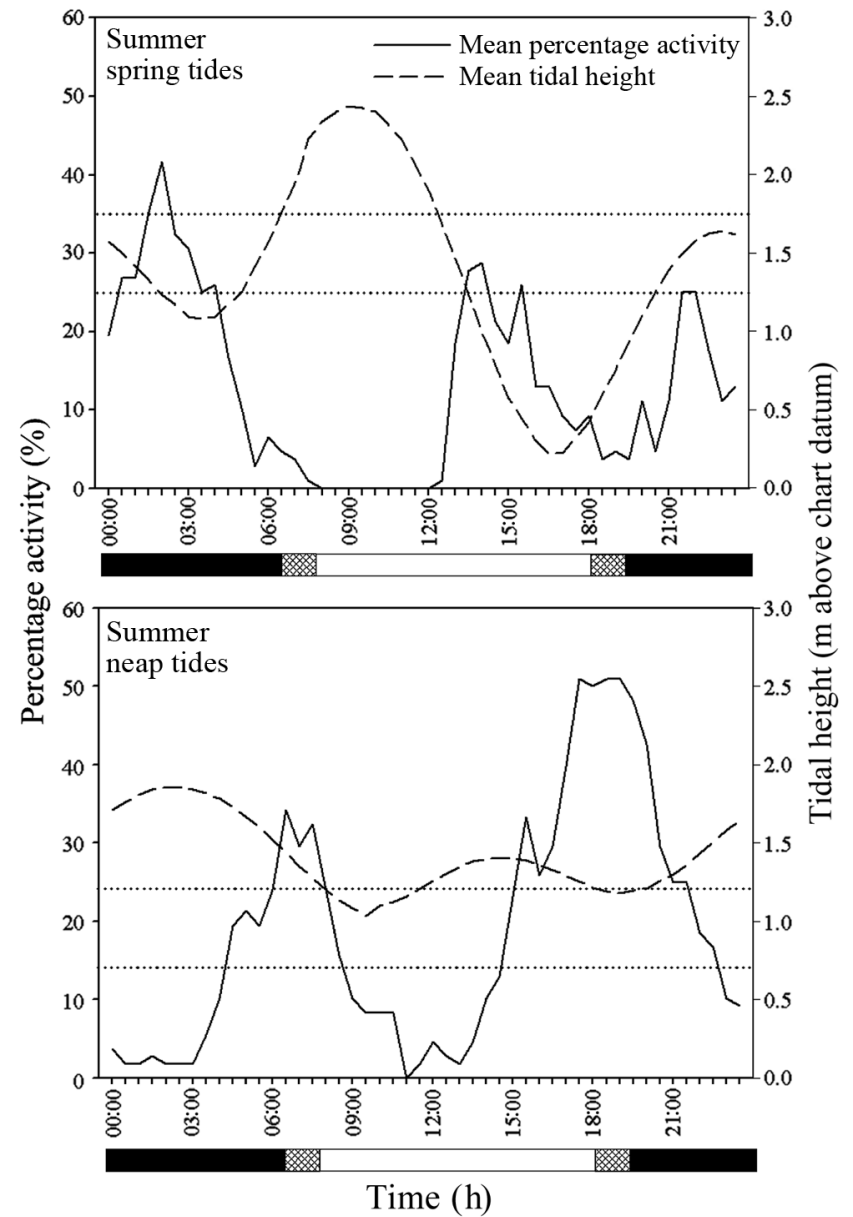

Fig. 2. Nerita yoldii. Mean percentage activity and tidal height on summer spring and neap tide days, calculated from the average values of 3 observation days at 2 sites. Dotted horizontal lines represent the abundant zone of tracked individuals. Open horizontal bars indicate daytime, solid bars nighttime and hatched bars dusk or dawn (results for individual days are given in Fig. S1A-D in the Supplement)

On summer spring tides, there was no activity during the morning high tide period until the tide dropped below $1.75 \mathrm{~m}$ above CD (Figs. 1 \& 2). Percentage activity then rose to form the first peak during the daytime ebbing tide in the afternoon (the lower of the low tides on spring tide days, $\sim 0.5 \mathrm{~m}$ above $\mathrm{CD}$ ). After this, the activity dropped to a trough, when individuals were dry and emersed by the low tide. The tide then rose to the lower of the 2 high tides of the day (to $\sim 1.0 \mathrm{~m}$ above $\mathrm{CD}$ ), after which the second peak of activity was recorded on the ebbing tide when individuals were on wet, emersed rock surfaces (Figs. $1 \& 2$ ). Activity decreased again as the tide rose to cover the nerites, and no activity was recorded when the tidal level was $>1.75 \mathrm{~m}$ above $\mathrm{CD}$ and all individuals were immersed (Figs. $1 \& 2$ ). Two activity peaks were also recorded on summer neap tide days (Figs. 1 \& 2), beginning when the tide ebbed and individuals were awash, and ending with the rising tide when individuals were immersed $(>1.75 \mathrm{~m}$ above $\mathrm{CD}$ ). This pattern was repeated twice every day when the tidal level ranged between 1.0 and $1.5 \mathrm{~m}$ above $\mathrm{CD}$. The activity peaks during the afternoon and night ( 14:00 to 00:00 h) were greater $(\sim 60 \%)$ that those during the morning $(\sim 40 \%$, $\sim 03: 00$ to $12: 00 \mathrm{~h}_{\text {i Figs. } 1} \&$ 2) on all neap days.

Activity was much lower on winter spring tide days than in the summer and was highest when the tide ebbed from the midnight high tide when the tidal level was $\sim 0.5$ to $1.5 \mathrm{~m}$ above CD (Figs. 1-3). As well as this peak, a smaller peak $(<20 \%)$ was recorded between $\sim$ 12:00 and 19:00 h (Figs. 1 \& 3). On winter neap tide days, activity was greatest $(\sim 50 \%)$ when the tide ebbed from the midday high tide $(\sim 16: 00$ to $03: 00 \mathrm{~h}$ ) and individuals were on wet, emersed surfaces (Figs. 1 \& 3). Activity decreased, however, when the tide rose above $1.5 \mathrm{~m}$ above $\mathrm{CD}$ but

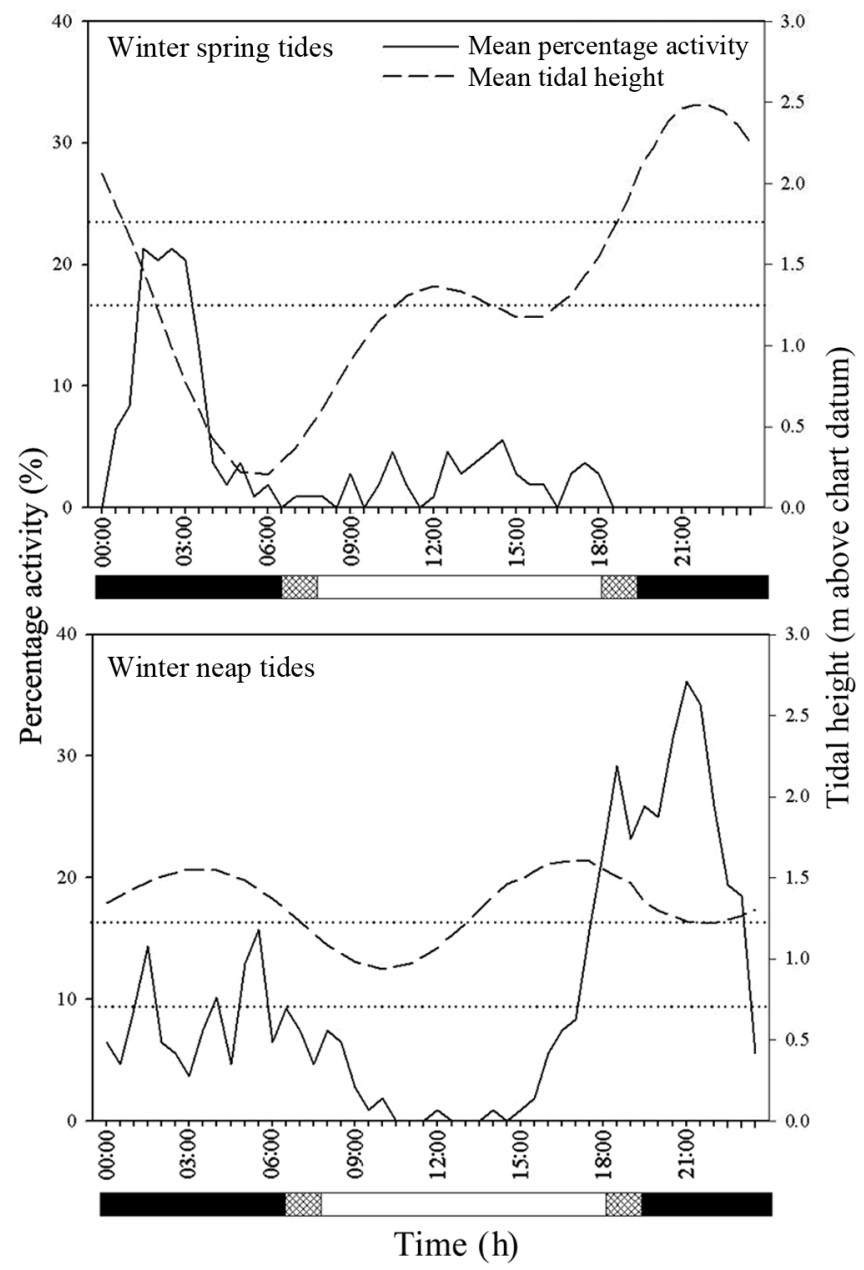

Fig. 3. Nerita yoldii. As in Fig. 2, but for winter tides 
increased again and formed another, smaller ( 20\%) peak when the tide ebbed again in the morning ( 03:00 to $16: 00$ h; Figs. 1 \& 3).

\section{Temporal variation in foraging parameters}

The resultant vectors of the furthest point traveled from the initial refuge (outward phase) were close to

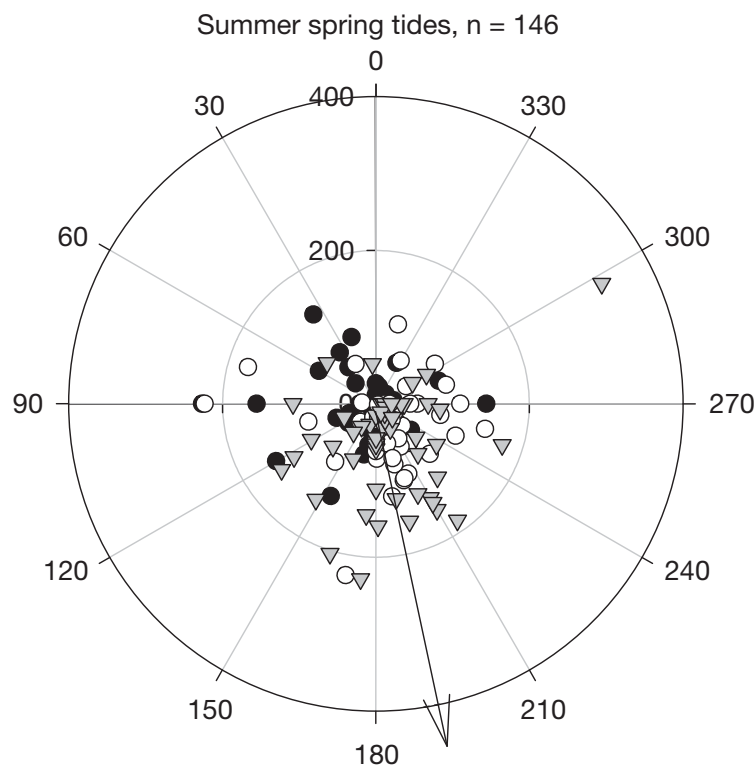

Resultant vector: $193^{\circ}, 29.7 \mathrm{~cm}, \mathrm{z}=29.57, \mathrm{p}<0.01$ $180^{\circ}$ (i.e. downwards) for both seasons and tidal conditions (Fig. 4) and were generally longer in summer and on neap tide days (Fig. 4). The resultant vectors from the furthest point traveled to final refuges (return phase) were close to $0^{\circ}$ (i.e. upwards) during both seasons and tidal conditions (Fig. 5). Rayleigh's test showed that directions of all resultant vectors were significantly different from a uniform distribution. The distance of the resultant vectors towards the furthest point

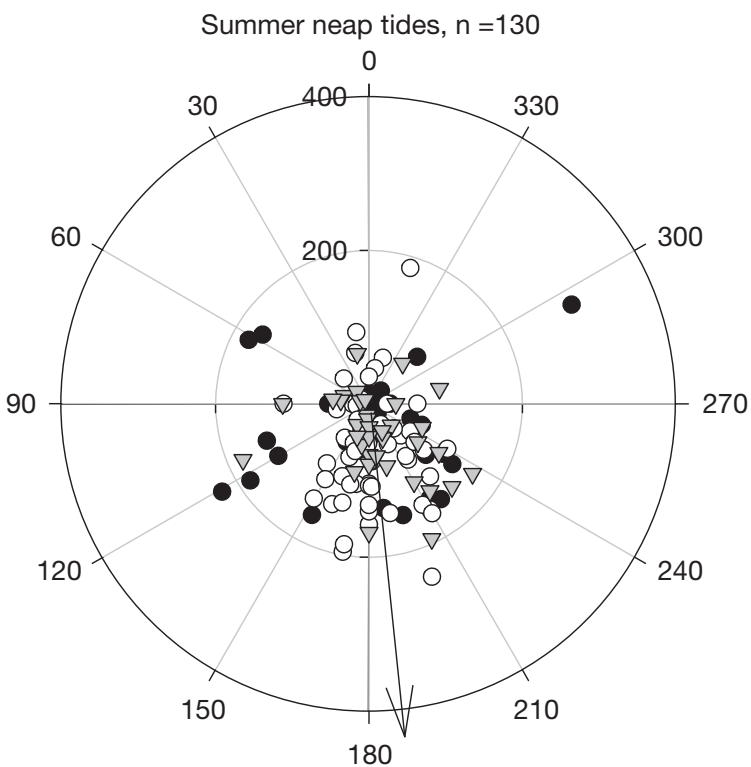

Resultant vector: $186^{\circ}, 47.6 \mathrm{~cm}, \mathrm{z}=31.30, \mathrm{p}<0.01$

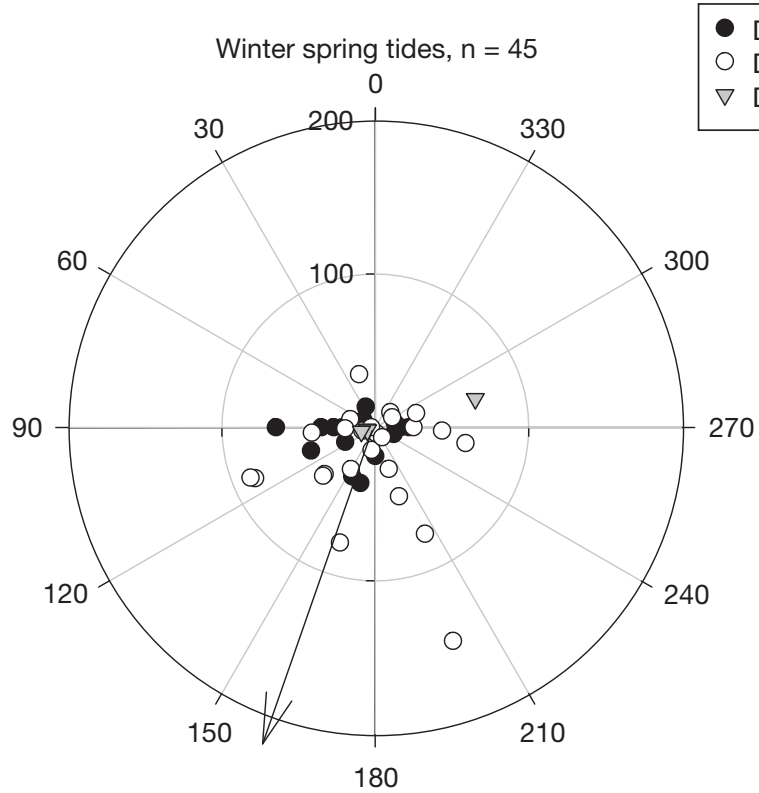

Resultant vector: $159^{\circ}, 13.7 \mathrm{~cm}, \mathrm{z}=4.46, \mathrm{p}<0.05$

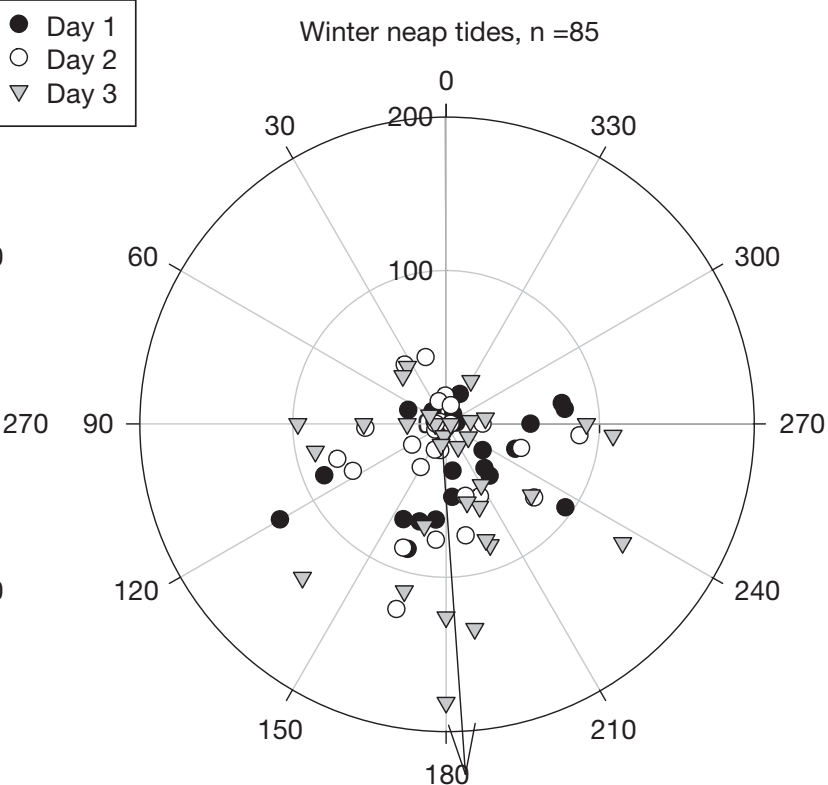

Resultant vector: $183^{\circ}, 25.9 \mathrm{~cm}, \mathrm{z}=10.49, \mathrm{p}<0.001$

Fig. 4. Nerita yoldii. Variation in the maximum foraging displacement and direction of $N$. yoldii from initial refuge to furthest point traveled (outward phase), and the resultant vectors for different seasons and tidal conditions; $\mathrm{n}$ represents the number of recorded foraging excursions 
traveled and towards the final refuges were generally higher in summer and on neap tides (Figs. 4 \& 5).

In general individuals moved further from refuges, at greater speeds and for longer durations (Table 2, Fig. 6) in summer than in winter. Foraging range and maximum speed showed a significant interaction between season and tidal condition (Table 2, Fig. 6). In summer, both foraging parameters did not show large variation between tidal conditions; however,

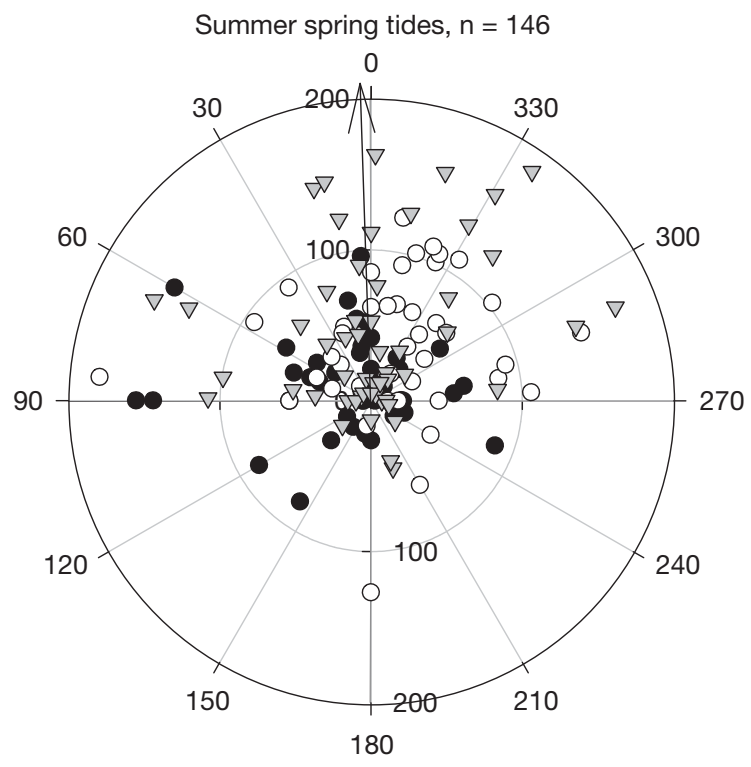

Resultant vector: $3^{\circ}, 33.6 \mathrm{~cm}, \mathrm{z}=29.00, \mathrm{p}<0.01$ in winter both were greater on neap than on spring tides (Fig. 6). Variation between sampling days $(\mathrm{Da}(\mathrm{Se} \times \mathrm{Ti})$ in Table 2, nested within the interaction of season and tidal condition) was also highly significant in all tests (Table 2). Daily variation could be seen in all measured parameters, such as on Day 3 of the summer neap tide recordings when nearly all foraging parameters were reduced as compared to other summer neap tide days (Fig. 6). In contrast, on

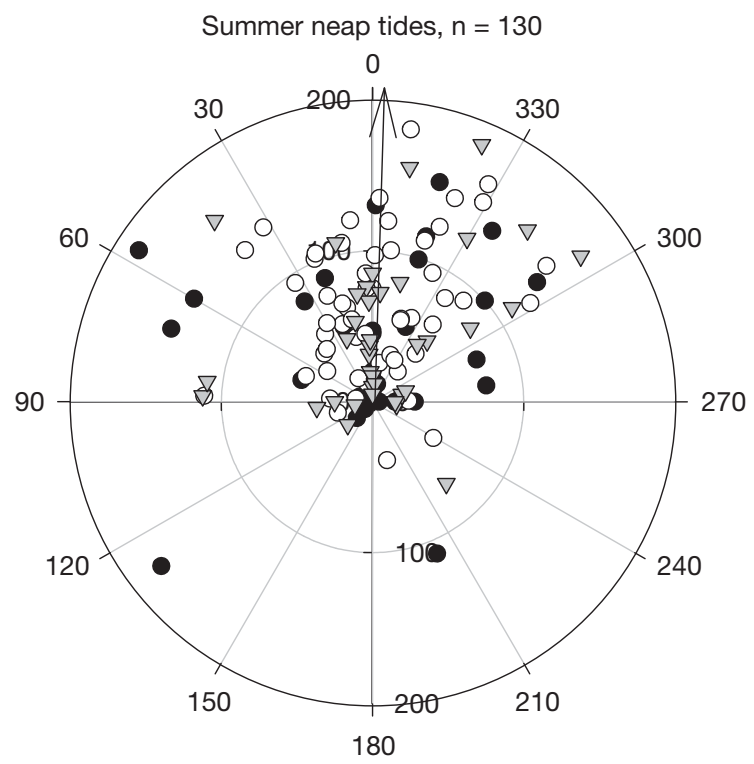

Resultant vector: $357^{\circ}, 50.0 \mathrm{~cm}, \mathrm{z}=52.73, \mathrm{p}<0.01$

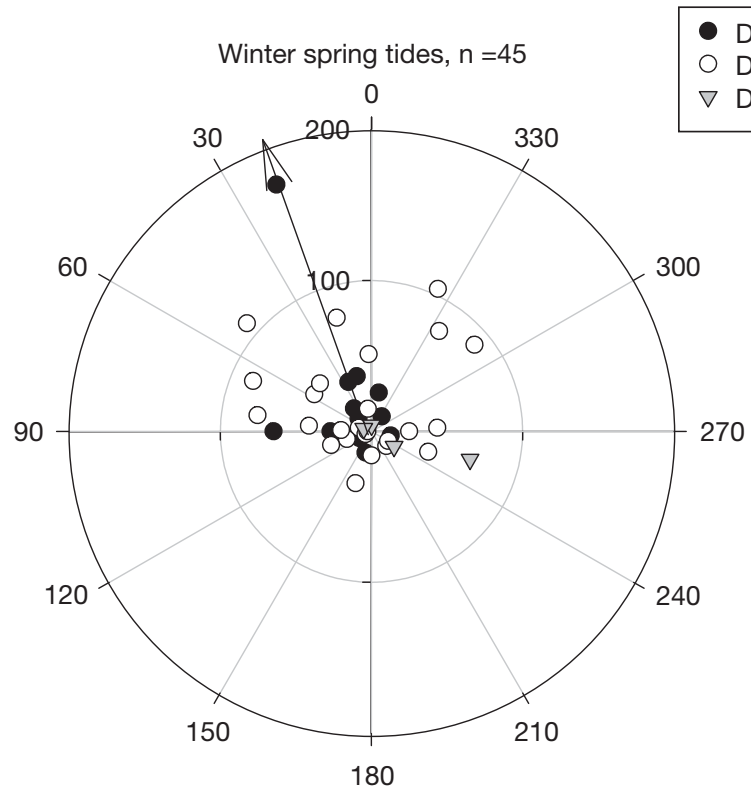

Resultant vector: $25^{\circ}, 17.3 \mathrm{~cm}, \mathrm{z}=4.47, \mathrm{p}<0.05$

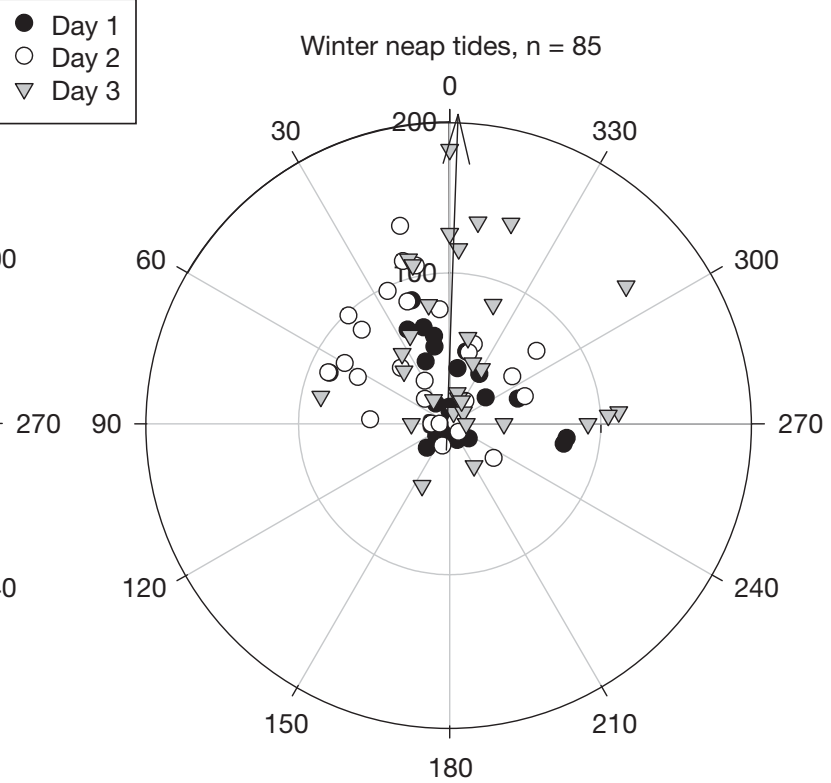

Resultant vector: $359^{\circ}, 36.6 \mathrm{~cm}, \mathrm{z}=41.5, \mathrm{p}<0.01$

Fig. 5. Nerita yoldii. Variation in the maximum foraging displacement and direction of $N$. yoldii from the furthest point traveled to final refuge (return phase), and the resultant vectors for different seasons and tidal conditions; $\mathrm{n}$ represents the number of recorded foraging excursions 
Table 2. Nerita yoldii. Summary of F-ratios and SNK multiple comparison tests after 3-way, mixed model ANOVA to investigate variation in 4 foraging parameters: total distance traveled, foraging range, maximum speed and activity duration between season (Se, fixed and orthogonal), tidal condition ( $\mathrm{Ti}$, fixed and orthogonal) and sampling day [ $\mathrm{Da}(\mathrm{Se} \times \mathrm{Ti})$, random and nested within season and tidal condition]; $\Sigma \mathrm{n}=2 \mathrm{Se} \times 2 \mathrm{Ti} \times 3 \mathrm{Da} \times 36$ individuals (sites were pooled) $=432$. Values in parentheses are error mean squares. Cochran's test for homogeneity, $C=0.11,0.13,0.12$ and $0.13(\mathrm{p}>0.05)$ after natural log transformation for foraging range and square root transformation for total distance traveled, maximum speed and activity duration, respectively. Significant factors are indicated by ${ }^{*} p<$ 0.05 and ${ }^{* * *} \mathrm{p}<0.001$

\begin{tabular}{|lccccc|}
\hline Source & df & $\begin{array}{c}\text { Total distance } \\
\text { traveled } \\
(27.71)\end{array}$ & $\begin{array}{c}\text { Foraging } \\
\text { range } \\
(2.222)\end{array}$ & $\begin{array}{c}\text { Maximum } \\
\text { speed } \\
(7.17)\end{array}$ & $\begin{array}{c}\text { Activity } \\
\text { duration } \\
(0.239)\end{array}$ \\
\hline $\mathrm{Se}$ & 1 & $38.64^{* * *}$ & $35.99^{* * *}$ & $47.33^{* * *}$ & $27.37^{* * *}$ \\
$\mathrm{Ti}$ & 1 & 4.80 & $4.03^{* *}$ & $4.92^{*}$ & 3.90 \\
$\mathrm{Se} \times \mathrm{Ti}$ & 1 & 2.22 & $6.02^{*}$ & $7.81^{* * *}$ & 2.02 \\
$\mathrm{Da}(\mathrm{Se} \times \mathrm{Ti})$ & 8 & $7.21^{* * *}$ & $4.99^{* * *}$ & $4.22^{* * *}$ & $8.05^{* * *}$ \\
$\mathrm{Residual}$ & 420 & & & & \\
\hline
\end{tabular}

the third day of the winter spring tide recordings all foraging parameters were lower than on other winter spring tide days. These interactions clearly showed daily variation in the intensity of foraging behaviour within the normal predictable pattern.

\section{DISCUSSION}

\section{General patterns of foraging}

Zann (1973) suggested that nerite foraging behaviour is related to tidal level: low shore nerites are active when they are emersed during low tide, whilst high shore nerites are active during high tide (Zann 1973, Chelazzi 1982). As such,
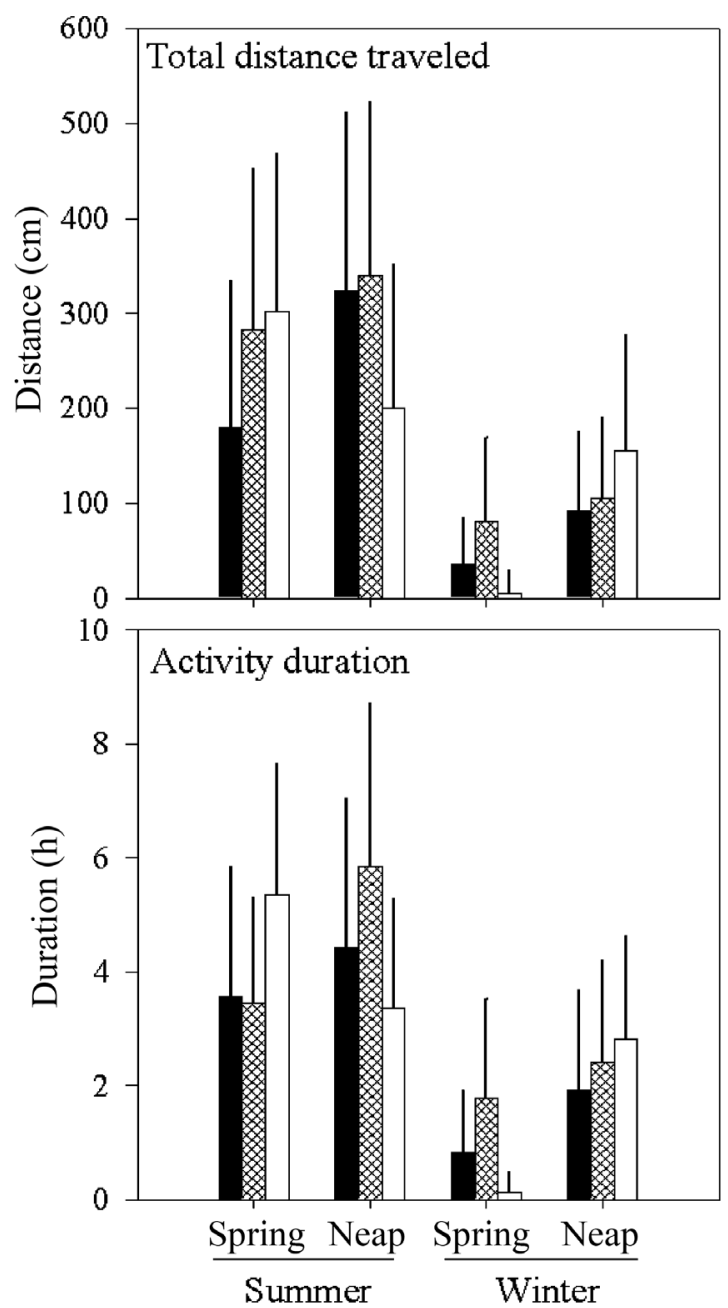
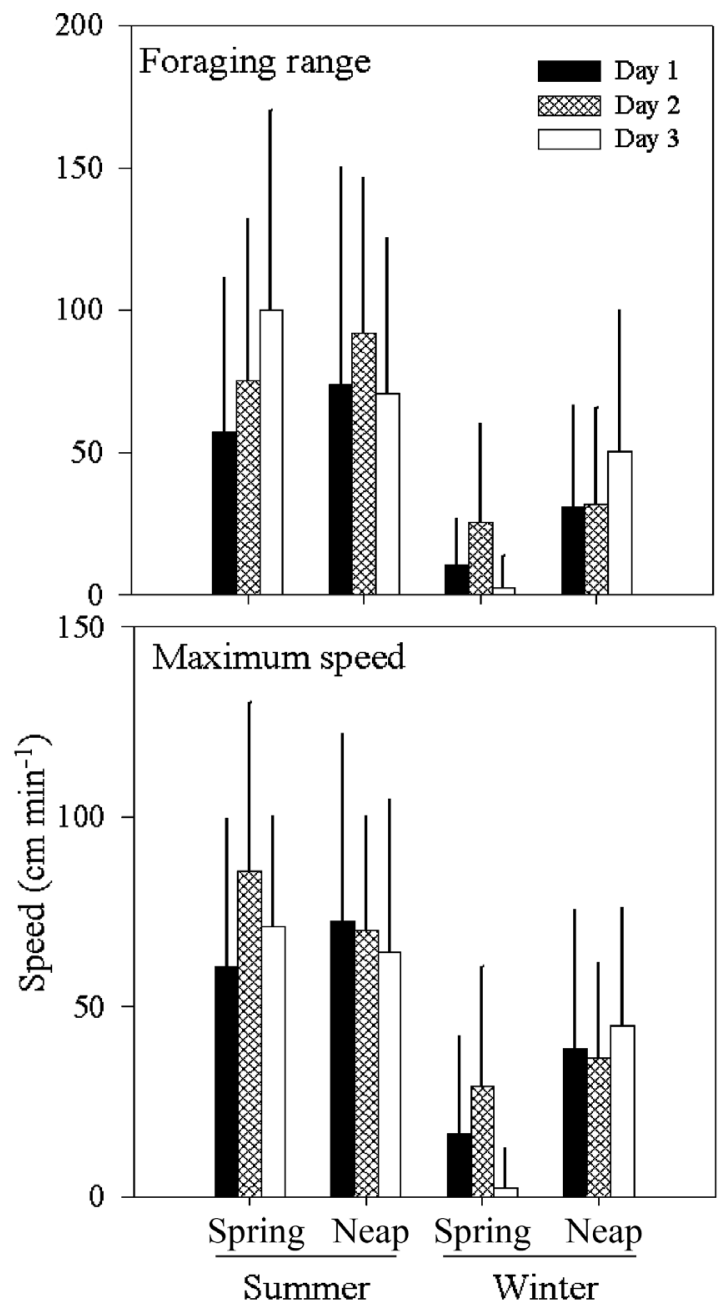

Fig. 6. Nerita yoldii. Mean (+SD) daily variation in the total distance traveled, foraging range, maximum speed and activity duration in different seasons (summer and winter) and tidal conditions (spring and neap) 
Nerita yoldii showed a typical, low-shore nerite foraging behaviour. The activity pattern of $N$. yoldii is generally predictable, foraging when awash or emersed, which is similar to behaviour of N. scabricosta and N. funiculata in Panama (Levings \& Garrity 1983). As with other Nerita species (Chelazzi et al. 1988), N. yoldii are zonal shuttlers, moving down shore when the water level drops, and foraging above and moving behind the retreating tide. The mid-shore feeding zone (an area rich in filamentous cyanobacteria and diatoms) of $N$. yoldii was generally lower on the shore than their refuges. Moving downshore to forage may, therefore, increase the probability that an individual will encounter a rich food supply (Lubchenco \& Gaines 1981). As the tide rises, the nerites moved back upshore ahead of the flooding tide to take shelter in refuges. During high tide, $N$. yoldii became immersed and were inactive in crevices, which is similar to the high- to mid-shore $N$. funiculata, which seek refuges to avoid the high risk of predation from fish during high tide, or from crabs during nocturnal emersion periods in Panama (Levings \& Garrity 1983). In contrast, on the same shores in Panama, the higher-shore neritid, N. scabricosta, which also forages whilst awash, is able to avoid risk of predation by fish whilst immersed by aggregating above the high tide mark. These differences in foraging behaviour in species co-occuring on the same shore confirm the importance of shore level in determining species' potential foraging strategies (Zann 1973, Levings \& Garrity 1983, Williams \& Little 2007).

The foraging behaviour of nearly all intertidal gastropods shows some relation to tidal conditions (Hawkins \& Hartnoll 1983, Williams \& Little 2007). Various causes have been proposed to drive these behaviours (Little 1989). The lack of activity of Nerita yoldii during immersion may, for example, be due to predation risk, and many low-shore Nerita species are active only during low tide when they are emersed or awash (Levings \& Garrity 1983). Experiments on N. scabricosta and N. funiculata, for example, showed that nerites placed experimentally underwater on open rock surfaces, or offered to fish in experimental tanks, suffered heavy mortality from puffer (Diodon spp.) and porcupine (Arothron spp.) fish (Levings \& Garrity 1983). Local muricid gastropods are reported to feed on nerites (Taylor \& Morton 1996), and mainly forage during high tide when they are immersed by the tide (Chow 2004). Predation risk may, therefore, limit $N$. yoldii's activities during immersion and force the species to inhabit refuges, although there is no direct evidence for this.
In the present study, most Nerita yoldii were inactive on dry, emersed substrata and during daytime emersion, especially on afternoon summer low tides, and most hid in refuges (crevice or pools) where temperatures were lower than on the adjacent open rock surface (Williams \& Morritt 1995). Physical factors, such as desiccation, osmotic and thermal stress, are known to limit activity during emersion, as suggested for N. scabricosta (Levings \& Garrity 1983) and N. forskalii and N. polita (Safriel 1969).

\section{Environmental variables and temporal variation}

Various foraging parameters of Nerita yoldii, similar to other intertidal gastropods, appear to be extremely labile, varying with time over various scales (including season and tidal condition and on a daily basis, Burrows \& Hughes 1989, Little 1989, Williams \& Little 2007). Previous studies have shown Nerita species exhibit larger temporal variability in grazing activities compared with other grazers (Forrest et al. 2001, Wai \& Williams 2006). N. yoldii exhibited clear seasonal variability in behaviour, foraging for $\sim 5 \mathrm{~h} \mathrm{~d}^{-1}$ in summer, which is similar to $N$. polita and $N$. textilis (Chelazzi 1982), but only $\sim 2 \mathrm{~h} \mathrm{~d}^{-1}$ in winter. Percentage activity was also generally higher in summer than in winter, with individuals foraging for longer, travelling greater distances, moving farther away from their refuges and achieving faster speeds. Variability in foraging behaviour between seasons has also been noted in many intertidal gastropods as a response to variation in environmental or intrinsic factors (reviewed by Chapman \& Underwood 1992a) and may have important consequences for growth and reproduction (Morais et al. 2003).

Variability in food availability can also contribute towards seasonal variation in foraging behaviour (Little 1989). The standing crop in the Hong Kong rocky intertidal is generally reduced in summer (Nagarkar \& Williams 1999). Individuals, therefore, would need to be 'more active' to obtain enough food to meet their metabolic requirements. A reduction in food availability has been proposed to drive individuals to forage more actively in Cellana tramoserica (Parry 1984), Collisella digitalis (Cubit 1984) and Monodonta labio (Takada 2001). The effect of seasonality on the activities of intertidal gastropods, however, varies with species. The limpet Helcion pectunculus, for example, exhibits higher activity in winter owing to increased wave action (Gray \& Hodgson 1997).

Temporal variation was also found between spring and neap tide days, activity being higher on neap 
than on spring tides. This is a function of time awash, as individuals are awash for longer on neap tide days (see also Ng \& Williams 2006). On spring tide days, in contrast, individuals are immersed for longer or dry and emersed, resulting in low activity. The monthly tidal cycle and the relative tidal height occupied by the nerites therefore largely determines foraging behaviour (see also a similar case in the limpet Cellana grata, Santini et al. 2011). Tidal conditions can, however, exhibit different effects on the foraging activities of intertidal gastropods. Nerita species in Kenya, for example, were more active on spring tides, which was suggested to be due to the changing amplitude of the tidal range (Ruwa \& Jaccarini 1988).

The percentage activity and all foraging parameters for Nerita yoldii varied between sampling days. Such temporal plasticity of foraging behaviour is probably due to daily variations in environmental conditions (Chapman \& Underwood 1992a), indicating that $N$. yoldii is able to modulate its behaviour in response to local changes in environmental conditions. Such plasticity may be important in ensuring that individuals maximize opportunities to gain energy, or minimize risk to extreme physical conditions (Mery \& Burns 2010). Events like rain can override other environmental conditions and modify the activities of intertidal gastropods (Lee \& Williams 2002). On a hot summer afternoon during preliminary observations, for example, most nerites were inactive as the rock surface was dry and the tide was low. A sudden rain shower, however, wet the rock and reduced rock temperature, stimulating the nerites to become active and forage until the rock surface became dry again (A. C. Y. Yeung pers. obs).

\section{Patterns of foraging excursions}

Nerita yoldii exhibited various patterns of foraging. Most active individuals in summer ( $63 \%)$ moved onto the open surface and then back to refuges. In contrast, in winter many ( $43 \%)$ individuals moved onto the open surface and then remained stationary, and finally moved back to refuges after being awash by the rising tide. The period of time individuals stayed on the open rock surface was longer in winter, although activity duration was higher in summer. Higher physical stress (heat stress and desiccation) during summer may force the active $N$. yoldii to return to their refuges after foraging to minimize the time spent on open rock surfaces (a time-minimization strategy, see Burrows \& Hughes 1991). This would minimize physical stress, and hence increase sur- vival, as high mortalities of intertidal organisms are recorded during afternoon low tides in summer (Williams \& Morritt 1995). In winter, on the other hand, the risk from physical stress is much lower, so the driving force to minimize the duration spent on open rock surfaces is reduced, and individuals can adopt more of an energy maximization strategy (see Evans \& Williams 1991, Santini et al. 2011). In these situations, the foraging pattern and the duration spent on open rock surfaces may only be limited during the immersion period (e.g. owing to marine predators). Individuals adopting this pattern may also benefit from greater amounts of food cropped, by foraging on open rock surfaces for longer (Burrows et al. 2000, Santini et al. 2011).

The present study shows that the foraging behaviour of Nerita yoldii has a general pattern, probably as a result of predictable environmental conditions (season and tidal changes). Within this pattern, however, it is highly labile as a response to day-to-day, local variation in other environmental factors such as air temperature (see Williams \& Little 2007, Mery \& Burns 2010). This small-scale temporal lability may be important in habitats where day-to-day changes may exceed tolerance limits of snails, such as on tropical shores (see Santini et al. 2011 for similar responses in a limpet, Cellana grata), and allow species such as $N$. yoldii to be successful in such extreme environments.

Acknowledgements. This work was conducted in partial fulfillment for a PhD thesis by A.Y.C.Y. and supported by a University of Hong Kong studentship. We are grateful to D. Wang, F. Lam, P. Chan and S. Cartwright for help with fieldwork, and to Prof. D. Dudgeon, Dr. V. Thiyagarajan (The University of Hong Kong) and G. Santini (Florence University) for comments on the manuscript. C. Law and R. Wong helped prepare the figures. The work described in this paper complies with the current laws of the Hong Kong SAR.

\section{LITERATURE CITED}

Batschelet EB (1981) Circular statistics in biology. Academic Press, London

Burrows MT, Hughes RN (1989) Natural foraging in the dogwhelk, Nucella lapillus (Linnaeus); the weather and whether to feed. J Molluscan Stud 55:285-295

Burrows MT, Hughes RN (1991) Optimal foraging decision by dogwhelks, Nucella lapillus (L.): influences of mortality risk and rate-constrained digestion. Funct Ecol 5: 461-475

Burrows MT, Santini G, Chelazzi G (2000) A state-dependent model of activity patterns in homing limpets: balancing energy returns and mortality risks under constraints on digestion. J Anim Ecol 69:290-300

Chapman MG, Underwood AJ (1992a) Foraging behaviour of marine benthic grazers. In: John DM, Hawkins SJ, 
Price JH (eds) Plant-animal interactions in the marine benthos. Syst Assoc Spec Vol 46. Clarendon Press, Oxford, p 289-317

Chapman MG, Underwood AJ (1992b) Experimental designs for analyses of movements by molluscs. In: Grahame J, Mill PJ, Reid DG (eds) Proc 3rd Int Symp Littorinid Biol, Dale Fort Field Centre, Wales, 5-12 Sep 1990. Malacol Soc Lond, London, p 169-180

Chelazzi G (1982) Behavioural adaptation of the gastropod Nerita polita L. on different shores at Aldabra Atoll. Proc R Soc Lond B Biol Sci 215:451-467

Chelazzi G, Innocenti R, Della Santina P (1983) Zonal migration and trail-following of an intertidal gastropod analyzed by LED tracking in the field. Mar Behav Physiol 10:121-136

Chelazzi G, Focardi S, Deneubourg JL (1988) Analysis of movement patterns and orientation mechanisms in intertidal chitons and gastropods. In: Chelazzi G, Vannini M (eds) Behavioural adaptation to intertidal life. Plenum Press, New York, NY, p 173-184

Chow CY (2004) Foraging behaviour of Thais clavigera: the interplay of environmental variation and predator behaviour on sheltered rocky shores. MPhil thesis, University of Hong Kong

Cubit JD (1984) Herbivory and the seasonal abundance of algae on a high shore intertidal rocky shore. Ecology 65: 1904-1917

> Erlandsson J, Kostylev VE, Williams GA (1999) The effect of surface complexity on movement tortuosity of a tropical limpet, Cellana grata (Gould): a new method of describing spatial foraging patterns of rocky shore gastropods. Ophelia 50:215-224

> Evans M, Williams GA (1991) Time partitioning of foraging in the limpet, Patella vulgata (L.). J Anim Ecol 60: 563-575

- Forrest RE, Chapman MG, Underwood AJ (2001) Quantification of radular marks as a method for estimating grazing of intertidal gastropods on rocky shores. J Exp Mar Biol Ecol 258:155-171

> Gray DR, Hodgson AN (1997) Temporal variation in foraging behaviour of Patella granularis (Patellogastropoda) and Siphonaria concinna (Basommatophora) on a South African shore. J Molluscan Stud 63:121-130

Hartnoll RG, Wright JR (1977) Foraging movements and homing in the limpet Patella vulgata L. Anim Behav 25:806-810

Hawkins SJ, Hartnoll RG (1982) The influence of barnacle cover on the numbers, growth and behaviour of Patella vulgata on a vertical pier. J Mar Biol Assoc UK 62: 855-867

Hawkins SJ, Hartnoll RG (1983) Grazing of intertidal algae by marine invertebrates. Oceanogr Mar Biol Annu Rev 21:195-282

Hill DS (1980) The Neritidae (Mollusca: Prosobranchia) of Hong Kong. In: Morton B (ed) Proceedings of the first international workshop on malacofauna of Hong Kong and Southern China. Hong Kong University Press, Hong Kong, p 85-99

Kaehler S, Williams GA (1996) Distribution of algae on tropical rocky shores: spatial and temporal patterns of noncoralline encrusting algae in Hong Kong. Mar Biol 125: 177-187

Lee OHK, Williams GA (2002) Locomotor activity patterns of mangrove littorinids, Littoraria ardouiniana and L. melanostoma, in Hong Kong. J Molluscan Stud 68:235-241
Levings SC, Garrity SD (1983) Diel and tidal movement of two co-occurring neritid snails; differences in grazing patterns on a tropical rocky shore. J Exp Mar Biol Ecol 67:261-278

Little C (1989) Factors governing patterns of foraging activity in littoral marine herbivorous molluscs. J Molluscan Stud 55:273-284

Little C, Williams GA, Morritt D, Perrins JM, Stirling P (1988) Foraging behaviour of Patella vulgata L. in an Irish sea-lough. J Exp Mar Biol Ecol 120:1-21

Lubchenco J, Gaines SD (1981) A unified approach to marine plant-herbivore interactions. I. Populations and communities. Annu Rev Ecol Syst 12:405-437

Mery F, Burns JG (2010) Behavioural plasticity: an interaction between evolution and experience. Evol Ecol 24: 571-583

> Morais S, Boaventura D, Narciso L, Ré P, Hawkins SJ (2003) Gonad development and fatty acid composition of Patella depressa Pennant (Gastropoda: Prosobranchia) populations with different patterns of spatial distribution, in exposed and sheltered sites. J Exp Mar Biol Ecol 294: $61-80$

Morton B, Williams GA, Lee SY (1996) The benthic marine ecology of Hong Kong: a dwindling heritage? In: Coastal infrastructure development in Hong Kong: a review. Civil Engineering Department, Hong Kong SAR Government, p 223-267

Nagarkar S, Williams GA (1999) Spatial and temporal variation of cyanobacteria-dominated epilithic communities on a tropical shore in Hong Kong. Phycologia 38:385-393

Ng JSS, Williams GA (2006) Intraspecific variation in foraging behaviour: influence of shore height on temporal organization of activity in the chiton Acanthopleura japonica. Mar Ecol Prog Ser 321:183-192

> Parry GD (1984) The effect of food deprivation on seasonal changes in the metabolic rate of the limpet, Cellana tramoserica. Comp Biochem Physiol A Physiol 77:663-668

> Ruwa RK, Jaccarini V (1988) Nocturnal feeding migrations of Nerita plicata, N. undata and N. textilis (Prosobranchia: Neritacea) on the rocky shores at Mkomani, Mombasa, Kenya. Mar Biol 99:229-234

Safriel V (1969) Ecological segregation, polymorphism and natural selection of two intertidal gastropods of the genus Nerita at Eilat (Red Sea, Israel). Israel J Zool 18: 205-231

> Santini G, Thompson RC, Tendi C, Hawkins SJ, Hartnoll RG, Chelazzi G (2004) Intraspecific variability in the temporal organization of foraging activity in the limpet Patella vulgata. Mar Biol 144:1165-1172

> Santini G, Ngan A, Williams GA (2011) Plasticity in the temporal organization of behaviour in the limpet Cellana grata. Mar Biol 158:1377-1386

Takada Y (2001) Activity patterns of the herbivorous gastropod Monodonta labio on a boulder shore at Amakusa, Japan. Venus 60:15-25

Taylor JD, Morton B (1996) The diets of predatory gastropods in the Cape d'Aguilar marine reserve, Hong Kong. Asian Mar Biol 13:141-166

Vermeij GJ (1973) Morphological patterns in high-intertidal gastropods: adaptive strategies and their limitations. Mar Biol 20:319-346

Wai TC, Williams GA (2006) Monitoring spatio-temporal variation in molluscan grazing pressure in seasonal, tropical rock pools. Mar Biol 149:1139-1147

Williams GA, Little C (2007) Foraging behavior. In: Gaines 
S, Denny M (eds) Encyclopedia of tide pools and rocky shores. University of California Press, Berkeley, CA, p 239-242

Williams GA, Morritt D (1991) Patterns of foraging in Patella vulgata (L.). In: Myers A, Little C, Costello M, Partridge J (eds) The ecology of Lough Hyne. Royal Irish Academy, Dublin, p 61-69

Williams GA, Morritt D (1995) Habitat partitioning and thermal tolerance in a tropical limpet, Cellana grata. Mar Ecol Prog Ser 124:89-103

Williams GA, Little C, Morritt D, Stirling P, Teagle L, Miles

Editorial responsibility: Hans-Heinrich Janssen,

Oldendorf/Luhe, Germany
A, Pilling G, Consalvey M (1999) Foraging in the limpet Patella vulgata: the influence of rock slope on the timing of activity. J Mar Biol Assoc UK 79:881-889

Yeung ACY (2006) The ecology of Nerita yoldii and N. albicilla on Hong Kong rocky shores. PhD thesis, University of Hong Kong

Zann LP (1973) Relationships between intertidal zonation and circatidal rhythmicity in littoral gastropods. Mar Biol 18:243-250

Zar JH (1999) Biostatistical analysis. Prentice Hall, Upper Saddle River, NJ

Submitted: May 4, 2011; Accepted: May 2, 2012

Proofs received from author(s): August 1, 2012 